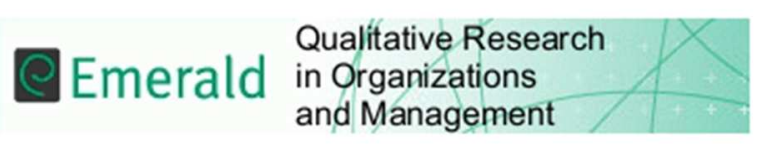

\title{
Shadow organizing: a metaphor to explore organizing as intra-relating
}

\begin{tabular}{|r|l|}
\hline Journal: & Qualitative Research in Organizations and Management \\
\hline Manuscript ID & QROM-06-2016-1385.R1 \\
\hline Manuscript Type: & Original Article \\
\hline Keywords: & $\begin{array}{l}\text { agencement, liminality, metaphor, post-epistemology, performativity, } \\
\text { secrecy }\end{array}$ \\
\hline \multicolumn{2}{|l}{} \\
\hline
\end{tabular}

\section{SCHOLARONE \\ Manuscripts}




\begin{abstract}
Purpose: The present paper conceives 'organizing' as an indeterminate process taking place in the interstices of intra-acting elements, beyond visible/rational/intentional organizing. The term intraactivity refers to relationships between multiple elements (human and more-than-human) that are understood not to have clear or distinct boundaries. The paper aims at reframing organizing, as the effect of multiple intra-acting elements, by introducing the metaphor of shadow organizing. It offers examples as diverse as knowledge spillover, evidence-based medicine and improvisation, and the mafia's organizational rules.
\end{abstract}

Design/methodology: The frame of reference is metaphorical theorization, based on the metaphor of shadow organizing, and is explored through three metonymies: the forest and its sheltered spaces in penumbra; the shadow as a grey zone between canonical and non-canonical practices; and secret societies, hidden in the shadow. The shadow is the symbol of what is 'betwixt and between.'

Findings: Shadow organizing focuses on the way that situated elements (people, technologies, knowledges, infrastructures, society) intra-relate and acquire agency. Whilst organizing as the effect of intentional coordination, planning, and strategizing represents a well-established theorization, shadow organizing sheds light on what happen in the interstices of intentional and structured processes. The paper identifies the dimensions of shadow organizing as performativity, liminality, and secrecy.

Value: The passage from elements in interaction to intra-acting relations that form elements is a challenge both for theory and methodology. To face this challenge, metaphorical thinking proves useful since it enhances scholars' imaginations and emotional participation.

\title{
Introduction
}

When the term 'organizing' was introduced in organization studies by Weick (1979) and by March (1981), it operated like a quiet revolution in turning the attention of organization studies scholars 
from structures to processes, from organizations and their environments to organizing as an ongoing phenomenon across formal borders. The term 'organizing' marked the passage from a sociology of nouns to a sociology of verbs (Law, 1994) and therefore the neglect of the term 'organizations,' which refers to defined and socially legitimated units, and its replacement with the term 'organizing,' which refers to an activity, to a situated and pragmatic 'doing.' The term 'organizing' also collapsed the traditional dichotomy between formal and informal organizations, since central to the process of organizing are the relations forming a seamless web in which organizations are the outcomes of organizing, rather than vice versa. Organizing is also linked to the so-called practice turn in organizational studies (Author, 2009) that considers practices as the sites of working, learning, and organizing.

Whilst the term has proven to have had a tremendous effect, today we contend that it has operated an incomplete revolution, since its potentiality of being re-interpreted within the so called postepistemologies has not yet been fully explored. We use the expression post-epistemologies to embrace the debate on the blurring of the distinction between ontology and epistemology, nature and culture, and materiality and discursivity.

We are interested particularly in exploring the idea of intra-action as formulated by Karen Barad (2007: 139). For Barad, 'the primary ontological unit is not independent objects with inherent boundaries and properties but rather phenomena'; in other words, individuals (or things) do not preexist their interactions; rather, individuals and objects emerge through and as part of their entangled intra-relating. Intra-activity differs from inter-activity. The concept of inter-activity refers to a relationship between elements that are taken to be separate entities, as in an interpersonal relationship between two humans. The term intra-activity comes from physics and refers to relationships between multiple elements (human and more-than-human) that are understood not to have clear or distinct boundaries. Therefore, in using the concept of intra-activity, we propose to consider organizing as the effect of multiple intra-acting elements, always affecting or being 
affected by each other in an interdependent and mutual relationship. But how can we conceptualize intra-activity in organizing? This is the question that we address in this article.

To explore organizing as the effect of entangled intra-relating elements, we propose to resort to metaphorical thinking and writing through the metaphor of 'shadow organizing.' The main reason for qualifying organizing in the light of 'shadow' is to refresh the concept and look at it with new eyes. Moreover, shadow is in itself a powerful symbol, and its polysemy may become an interesting vehicle for thinking in terms of intra-actions using the images of the intertwining of light and dark, of grey tone as the entanglement of white and black, or in social imaginary the entanglement of transparency and secrecy.

The use of metaphors in organization studies, in organizational development, or in teaching is now well documented (Barley, 1983; Brown, 1976; Cassell and Lee, 2012; Morgan, 1980; 2016; Putman et al., 1996; Tsouskas, 1991), and there is widespread consensus that metaphors are far more than mere rhetorical devices in speech and writing. They are important means of generating new knowledge and understandings of social phenomena, and also for their emotional dimension. In fact, Höpfl and Maddrell (1996) remind us that 'emotion,' 'movement,' and 'motivation' share a common etymological root: from the Latin movere, to move. Therefore 'metaphors are important because they remind us that there is "no absolute world "out there", but that we are actively engaged in constructing meanings from our own frame of reference and experience' (Grant and Oswick, 1996).

To explore the dynamics of organizing that emerge in the process of constant and indeterminate intra-acting, we use the metaphor of shadow organizing ${ }^{i}$ that plays on these two concepts: organizing as an ongoing process and shadow as a symbol of what is 'betwixt and between.' Moreover, we expand the metaphor through a metonymic process that reveals how the term 'shadow' may be based on different images and analogies that nuance the metaphor differently. We shall follow Morgan's (2016: 1030) theorization on metaphorical thinking, assuming that metaphor operates through the juxtaposition of images (organizing is shadow) in a creative and expansive 
process; nevertheless, 'for metaphors to have specific meaning the metaphorical image needs to be tied down and articulated through a metonymical process focused on the naming of detailed elements.'

Consequently, we shall explore three metonymies of the shadow: 1) the forest and its sheltered spaces in penumbra; 2) the shadow as a liminal, grey zone between canonical and non-canonical practices; and 3) secret societies, hidden in the shadow. Moreover we shall illustrate how each metonymy illuminates different dimensions of shadow organizing, and we shall use examples as different as knowledge spillovers, improvisation at the borders between prescribed actions and professional discretion, and the mafia and its organizational rules.. For each example we have chosen an empirical study that we re-interpret using the shadow organizing metaphor. Our contribution to theorizing with the aid of metaphorical thinking is to show how the process of organizing in the interstices has the following dimensions: performativity, liminality, and secrecy.

The paper is organized as follows. First, we position the paper in relation to the ongoing but renewed debate (Örtenblad et al. 2016) in organization theory around metaphorical thinking and theorizing. Next, we introduce the debate on post-epistemologies in order to ground the metaphor of shadow organizing within it. This is followed by an examination of the three metonymies introduced earlier, each illustrated by an empirical example. We suggest that the concept of shadow organizing provides a sensitizing means through which to investigate situated, multiple, and complex relationships, taking place in-between the organizing elements, in their intra-relating.

\section{Are metaphors still useful for generating organizational knowledge?}

Metaphorical language is one of the most important devices by which knowledge is generated, and in the Aristotelian tradition, it is based essentially on an analogic process that sets A (the alreadyknown term) in relation to B (the term that one wishes to know). Thus meaning transpositions come into operation that make it possible to imagine and talk about the object in question (organizing, in our case) as if it were another already-known object (shadow). A metaphor works by matching what 
is distant with what is close, similar features with dissimilar ones. It is a tool for theory development that develops creativity and social imagination and reveals the importance of language and symbols in the construction of reality and in the formulation of ways of seeing and describing (Cornelissen et al., 2005; Cornelissen et al., 2011; Lakoff and Johnson, 1980). In the interaction between two separate domains, and in the projection of meaning between what is and what is not (Czarniawska, 2004), metaphors do not reveal similarities and analogies but rather create them. Their role is to see as and, therefore, to shape a system of representations (Cunliffe, 2003; Schon, 1979). 'Organizational culture' or 'organizational learning' are generative metaphors; they are 'world-making' devices (Author, 2000; Goodman, 1978). Moreover, metaphors are invaluable tools for qualitative data analysis, especially when researchers deal with ill-structured problems, since the elicitation of metaphors can bring new insights into the sensemaking processes of workers (Cassell and Bischop, 2012; Benozzo et al. 2013).

In organization studies, the publication of Gareth Morgan's book Images of Organization in 1986 constituted a ground-breaking event that invited organizational scholars to explore eight metaphors grounding the historical development of organization theory. The eight metaphors were as follows: the machine, the organism, the brain, the culture, the political system, the psyche prison, the flux and transformation, and the instrument of domination. They highlighted organizational theories ranging from Taylorism to critical theories. Thirty years after the publication of the book, the journal Human Relations dedicated a special issue to its celebration (Örtenblad et al., 2016), which witnesses that an interest in metaphorical thinking is still alive.

Metaphors are in relation to both theorizing and acting in the world. As Morgan (1980: 610) suggested, 'the process of metaphorical conception is the basic mode of symbolism, central to the way in which humans forge their experience and knowledge of the world in which they live.' And the role of language in the formulation of organizational theories has become clearer since the socalled 'linguistic turn' (Deetz, 2003). If we assume that language does not describe the world, but rather constructs it, then it is nonsensical to ask oneself what a metaphor means or to search for its 
abstract and universal meanings. Instead, the meaning of a metaphor resides in the situation in which it is used, in the community that uses it, and in the context of action generated by it. Moreover, those that hear and re-use a metaphor are just as responsible for its meaning as those who first introduced it into a conversation. As the conversation proceeds and the metaphor passes from mouth to mouth, its meaning changes with changes in the social relations mediated by it. Moreover, metaphors are also tools for organizing (Czarniawska-Joerges and Joerges, 1988), since by familiarizing the unknown, people with many different interests are provided with the indispensable ambiguity needed to unite them in a collective endeavor without necessarily requiring a consensus of opinion.

After so many years of organizational scholars developing metaphors for understanding organizational phenomena and speculating about what is a 'good' metaphor and what is not (Heracleous, 2003), we can wonder whether metaphors have been rendered incapable of having any further power and have become 'just common sense' or whether there is some space left for theorizing on organizations using their knowledge-generative power. A compelling critique of the role of metaphors in knowledge generation has been put forward by Oswick et al. (2002), who see metaphors operating in a 'cognitive comfort zone' of similarity, and therefore they operate an analytical closure that works more for disseminating knowledge than for generating new knowledge. On the contrary, the authors suggest that to resort to conceptual irony, rather than metaphor, would be more fruitful for generating knowledge. The binary distinction between similarity and dissimilarity leading to the distinction between disseminating and generating knowledge is quite dangerous, because it leads toward a distinction between weak and strong metaphors and leads one to look for clear cut boundaries between types of knowing instead of considering knowing as a situated activity that may benefit both from existing knowledge enacted in the process and new knowledge generated in the process of knowing.

Metaphors are better seen as modes of thinking, and, as Morgan (1996: 231) argued, 'a metaphorical image relies on some kind of metonymic reduction, otherwise it remains thin air.' For 
Morgan, metonymy relies upon metaphor and thus should be seen as a subclass of metaphor. The invitation to look for the interplay of metaphors and metonymies has been warmly advanced again by Morgan (2016) and Schoeneborn et al. (2016).

For example, Schoeneborn et al. (2016) illustrate the relation between metaphor and metonymy starting from Morgan's metaphor of organization as flux and transformation and elaborating three 'offspring' images of it: organization as becoming, organization as practice, and organization as communication. The authors, on the basis of the three images of flux, elaborate an analytical grid for imagining organizations in a paradoxical way — that is, as an entity and a process at the same time. They quote (Schoeneborn et al., 2016: 939) a well-known phrase: 'Who says that elephants can't dance?' as 'a good example of an image that keeps the notion of entity (the organization as elephant) in a fruitful tension with process (change as a form of dance)'. At the same time, we readers grasp in their example the reasons behind their use of metaphorical thinking in the tension between entity and process.

These considerations enable us to make a point about the use of metaphors in organizational thinking, and we can state that there are no metaphors that have a definite meaning within themselves, nor that there is a definite number of metaphors with which to interpret organizational life, and metaphorical thinking is still fruitful depending on certain conditions. One of these conditions is that the authoring of the metaphor (either by the researcher or the practitioner) through which to generate knowledge on a problematic aspect of our world is made explicit. For this reason, the next section is devoted to explaining the intents embedded within our proposal of the metaphor of shadow organizing.

\section{Shadow organizing and post-epistemologies}

While much work has been devoted to the discussion of metaphors for generating knowledge on 'organization' both as an empirical phenomenon and as a theory of organization, apparently the shift of attention from organization to 'organizing' did not changed the debate as could be 
anticipated by a change from an entity to an activity. We need an epistemological shift in order to leave 'fixed' elements behind us and to focus our attention to the intra-relating processes that allows elements to emerge.

In organization studies, Robert Cooper ${ }^{\text {ii }}$ has been a theoretical inspiration for thinking of organization as a social practice rather than a bounded thing in the world, for addressing questions about the distinction organization/disorganization (Cooper, 1986), and for introducing the challenge of 'relationality' in ways of knowing and representing the world (Cooper, 1992; 2010).

To illustrate the difference between a sociology grounded on distinct 'entities' and a sociology grounded on relationships, Cooper and Law (1995) employed the terms 'distal' and 'proximal' to designate two complementary but distinct ways of viewing human structures. In the former case social elements are conceived as self-sufficient, in the latter as beginnings and transformations which constantly renew themselves. Distal thought prioritizes results and consequences, the products and finished objects of thought and action, everything that is pre-packaged. Proximal thought instead addresses what is continuing and incomplete, towards which it constantly tends but never reaches. Human agency - as Robert Cooper (2005: 1690) discusses it- 'works by reflecting itself through meaningful connections with its environment. [..] Connections imply disconnections and both are necessary features of the interspace between the human agent and the objects that surround and support it'.

Therefore relationality is an invitation to see the world as the movement of relationships between things rather than the things in themselves, and it is this 'interspace' between the individual and its environment that is in the spotlight. The term 'relational epistemology' together with similar terms such as sociomaterial epistemology, practice epistemology, and post-qualitative epistemology are part of the same vocabulary, and they signal the blurring of the distinction between ontology and epistemology that followed the consolidation of the linguistic turn and the acknowledgement that both ontology and epistemology are discursive effects. 
For example, Barad (2003), who coined the cumbersome term 'epistemontology' (the study of practices of knowing in being), emphasizes that things and people constitute one another in the here-and-now through what she terms 'intra-action' and that subjects and objects are dynamically, agentially, and iteratively co-articulated in 'intra-action.' Therefore, she claims that 'knowing does not come from standing at a distance and representing but rather from a direct material engagement with the world' (Barad, 2007: 49). Thus, concepts such as sociomateriality, entanglement, intraaction, agencement, and becoming are part of the same vocabulary for questioning the traditional humanist qualitative research methodology and for exploring a post-humanist qualitative research in which entanglement makes all the categories of humanist qualitative research problematic.

Within a post-epistemological/post-humanist framework, aiming at decentering the human subject as the main agent of knowing, Patti Lather and Elizabeth St. Pierre (2013: 630) ask: 'How do we think a "research problem" in the imbrication of an agentic assemblage of diverse elements that are constantly intra-acting, never stable, never the same?' Inscribed in what can be called 'posthumanist' (as in the object-centered sociality of Knorr Cetina, 1997), agency is reconfigured as a capacity realized through the associations of humans and materiality (Latour, 2005), and discourse neither constructs 'reality' nor simply functions as its mirroring effect but rather causes discourse and materiality to co-emerge (Iedema, 2007). In thinking of organizing 'in a world without entities,' the concepts of co-constitution (Gergen, 2012), co-emergency, or intra-acting may prove useful. In fact, we need different metaphors and different ways of thinking when we want to generate knowledge within a post-epistemological framework, since relations take the place of object and images, like the machine, the organism, and the other employed by Morgan, are no longer able to evoke a state of constant connectivity and emergence.

When we consider 'organizing' within a post-humanist epistemology, we are assuming an activity of heterogeneous engineering (as termed by Law, 1987) or a process of agencement (the French word agencement, which has the idea of agency in its root, is preferable to the English assemblage). The problem, however, is that its translation into English as 'assemblage' — a final state- has 
changed the original meaning of agencement as the process of connecting. In fact, agencement recodes emergence and becoming (Venn, 2006), since it focuses on the dynamic character of the intra-relationships between the heterogeneous elements of the phenomenon, recognizing both structuring and indeterminate effects. Therefore 'organizing' as agencement recasts the structure/agency division, pointing to the process of linking heterogeneous elements in an openended process (Cooper, 1998; Author, 2016), and it fits better with the post-human epistemology of practice.

Going back to Morgan's vocabulary, 'organizing,' in our exploration of the metaphor of shadow organizing, represents the term that we wish to explore, while shadow stands for the term that we assume to know. Our task for the continuation of the exploration is to engage in a metonymic expansion of the metaphor. We shall explore three metonymies based on different images of shadow, and for each of them we shall offer an example of empirical research in organizational phenomena that can be attributed to the idea of shadow organizing as a specific process of agencement taking place beyond the surface of visible/rational/intentional organizing. We shall illustrate shadow organizing through the image of the forest and its sheltered spaces in penumbra; through the image of a liminal, grey zone between canonical and non-canonical practices; and of organizational secrecy, kept in-between the sayable and the unsayable.

\section{The shadow stands for a protective penumbra}

The shadow may convey the image of a forest where many trees protect the soil from direct light and retain the freshness of the humidity of the night. The trees in a forest provide an ecological environment of fertile soil where other forms of life can find their humus and good shelter in which to live. Like the trees, many organizations may provide similar opportunities for the growth of other organizations, without taking any responsibility for how they grow apart from simply 'being there' and letting them grow.

In this metonymy, the shadow represents the rich ecological conditions that harvest different forms 
of life. All the participants (human and non-human) intra-act in a sheltered environment, without binding commitments, and, at the same time, the ground for such connections is nurtured by the presence of the formal organizing mechanisms and institutions and their modes of fostering other experiences. Moreover, the shadow is the effect of the intertwinement of light and darkness, which intra-act to form a penumbra, and therefore the protective penumbra is an emerging, dynamic effect of light and dark intra-acting.

To give an example of organizational research in which the image of shadow organizing is implicitly at work, we can consider knowledge spillover in its relation with innovation. We have in mind processes where a firm acquires knowledge from the final product of another firm, or it obtains knowledge through the exploitation of knowledge, which is a public or semi-public good (news, patents or regulations), or it absorbs the knowledge of other actors through observation and imitation.

We can take the article by Munari et al. (2012) as a telling example of the literature on knowledge spillovers that argues that knowledge created within firms can be used freely by other economic agents once codified and transferred, and it generates positive externalities that foster innovative activities. According to this literature, most of the knowledge flowing is mainly tacit, difficult to codify, and usually it is transmitted through direct relationships requiring the spatial proximity typical of industrial districts. Therefore, firms situated in spatially concentrated economic systems have more innovation opportunities than those operating in scattered locations. The sharing of a common set of values and norms facilitates the development of multiple cooperative and competitive relations among actors that support the formation of dense networks of relationships, favoring the diffusion of knowledge and enhancing innovation opportunities with respect to competitors located outside the district.

Based on a longitudinal dataset in the automatic packaging machinery industrial district in Northern Italy, the authors (Munari et al., 2012: 429) 'show that: (i) firms within the district use local knowledge to a greater extent and more rapidly than knowledge from outside the district, (ii) focal 
firms use external knowledge to a greater extent than other firms operating in the district, and (iii) other (nonfocal) firms within the district rely on knowledge generated by focal firms to a greater extent than would be expected, given the geographic distribution of innovative activity in the industry.' The authors (Munari et al., 2012: 455) write also about an 'industrial atmosphere' that nurtures the innovation process.

The similitudes between organizing as a process driven by knowledge spillovers and the penumbra of a forest that provides the ecological conditions (an industrial district) for the growth of other species of plants under the shadow of the (focal) tree is a direct line. Then, we can ask: what do we learn about organizing processes?

This metonymy helps us to catch a dimension of organizing in the dynamics between voluntary and involuntary connections in action. Moreover, we can qualify this dimension as the performativity of organizing practices in that relationships 'just happen' and are not always the effect of intentional human actions. If we consider knowledge spillovers as organizing devices, we can say that they are transformative if they perform transformations in the business world. We understand performativity according to Callon (2007: 315): 'performativity goes beyond human minds and deploys all the materialities comprising the socio-technical agencements that constitute the world in which these agents are plunged.'

\section{Shadow stands for a liminal and emerging grey zone between canonical and non-canonical practices}

Shadow organizing may be viewed as analogous to an activity taking place in a grey zone, in a space and time of ambiguous definition and of mutable relations, as in the tidemark between the sea and the sand, or in the liminal space of the threshold. Liminal activity, to use Turner's (1969) term, is an activity that relates to the metaphor of the 'threshold' (limen in Latin): the invisible line that separates and unites the inner and the outer, a symbol of transition and transcendence (Beech, 2011). The state or condition of liminality enables communication between the structure - the 
institutional organization of positions and/or actors - and what Turner (1969) calls 'anti-structure,' that is, the social dynamic, the communitas. Liminality is the condition of being betwixt and between.

In organizational studies, many concepts refer to this grey zone and to liminal activities; we can think of the term 'organizational slack' (Cyert and March, 1963) as the condition for testing and experimenting with innovations in a protected area. Alternatively, we can think of professional discretion in practice as a way to shed light on working and organizing in the intersection between what is prescribed by formal rules and what is practiced in order to get work done. Professional discretion is a good example of how organizing and working emerge in a grey zone left over for professionals as room for maneuvering.

The quintessence of professional work (Freidson, 2001) is the discretion that refers to professionals' use of their own reasoning, but, more generally, frontline workers also exert similar judgments and lines of reasoning as 'a matter of some subjectivity' within the existing rules and regulations (Lipsky, 2010). Professional discretion, moreover, is implied not only in traditional professional work but also in the delivery of public services where frontline workers are pressured by conflicting requirements from policy rules, their clients' needs, and their professional codes. More generally, any working practice is guided by a logic of contingency in connecting its heterogeneous elements to a sociotechnical agencement. Together, the canonical and non-canonical ways of organizing provide opportunities for professionals to become 'conveyors of liminality' (Guimarães-Costa and Cunha, 2013).

The focus on liminal activities helps us to see how processes at the threshold between the canonical and the non-canonical provide grey zones for improvising practices (Weick and Sutcliffe, 2007) that can more easily meet the need of handling continuity and change in a knowledge domain. We can think of healthcare settings, which have been studied as contexts characterized by institutionalized norms of accountability, in which highly professionalized and institutionalized knowledge has to be managed. 
The paper that we chose for illustrating shadow organizing as intra-acting elements in-between institutionalized norms of accountability and professional discretion is that of da Graça Batista et al. (2016), in which the authors observe in an emergency room the dynamics among the protocols coming from evidence-based medicine and the improvisation practices needed for facing the unique needs of the patients. Evidence-based medicine is an organizational device whose philosophy and use is extending not only into healthcare contexts but also into several other practice fields, and therefore in this example we can also see the performativity of an organizing device.

Professionals working in contexts characterized by a high degree of institutional complexity and by institutionalized norms of accountability feel the pressure of contrasting institutional logics, since they are required to adhere to the rules whilst they have the autonomy and responsibility to provide individualized care for their patients. Therefore, the authors argue that medical work in the emergency room confronts professionals with permanent paradoxes that they handle in the following way: 'on the one hand, medical staff uses clinical guidelines that aim to (a) ensure an adequate level of medical care and (b) prevent liabilities for the organization and its professionals. On the other hand, they work around guidelines via improvisations intended to accommodate particular cases that do not fall under the predictions of the protocol' (da Graça Batista et al., 2016: 419). In this way, the professionals express compliance while preserving autonomy, and they respond to the increasing institutionalization of evidence-based medicine by enacting their work as a combination of ostensive compliance and 'underlife' improvisation to different degrees, depending on experience and contingency. Particularly interesting is the authors' conclusion that the duality of improvisation, as simultaneously present and absent, enables flexible improvised performances that paradoxically end up reinforcing institutional pressures for standardization.

In this example, the metonymy of shadow organizing as the grey zone in which the limen uniting and dividing the prescriptive and the discretionary is at work illustrates one of the main characteristic of everyday organizing in practice, since working practices are enacted within a normative infrastructure requiring a logic of contingency that combines adherence to social and 
organizational rules and discretion. Thus the agencement of all the practice elements are contingently emerging from the intra-action of canonical and non-canonical practices.

\section{Shadow stands for maintaining secrecy}

Shadow organizing can be seen in an analogy to organizational secrecy (Costa and Grey, 2014) and secret societies. This image is useful for several purposes. The 'secret' may be hidden in broad daylight and inscribed in explicit regulations and habits or it may be constitutive of particular secret organizations.

A secret is the effect of the intra-action between what is said (and what can be said) and what should be kept unsaid. For example, firms engaged in innovating activities, such as high-tech organizations, need to maintain a high level of secrecy about their activities leading to patents, and legitimate organizations that derive benefits from secrecy will adopt mechanisms that are similar to those of secret and criminal organizations. Despite the widespread presence of secrecy in organizing activities, its study has been neglected, since the assumption about transparency and rationality has been dominant in organization studies. Nevertheless, a sociological approach to secrecy has a long history, from Weber (1922), who theorized the 'official secret,' to Simmel (1906), who studied secret societies in relation to how they regulate the degree of membership, or Goffman (1969), who pointed to the compartmental insulation with which the secret organization creates protective boundaries around its members, making them 'invisible.'

Today, the issue is how such bonds are formed and maintained in the new era of globalization, both in legitimate organizations and in criminal ones. Drawing on studies of financiers and terrorists, Knorr Cetina claims that change in the contemporary world is driven by micro processes that are put into effect by agile formations that can create trust and patterns of coordination on geographical scales and at degrees of complexity where traditional organizations are paralyzed. As Knorr Cetina (2005, p. 215) states: 'The texture of a global world becomes articulated through microstructural patterns that develop in the shadow of (but liberated from) national and local institutional patterns.' 
One example is how new educational providers offer learning opportunities in the shadow of formal education and take over some functions traditionally allocated to the university without bringing their activities into the official light of qualification routes, as described by Author B (forthcoming) in the case of legal education.

However, terrorism is the most publicly discussed form of secret societies, which, at the moment, obscures the most local criminal organizations such as the mafia in its different organizational forms. It has been noted (Catino, 2014) that different mafias, such as the American and Sicilian Cosa Nostra, the Ndrangheta, the Yakuza, or Triads, show a great similarity, since these criminal organizations, despite their historical and cultural differences, share common organizational problems. Starting from this consideration, we chose Catino's (2015) article to illustrate shadow organizing according to the metonymy of secrecy.

The author discusses the function of organizational rules in comparing the Sicilian and the American Cosa Nostra. His basic assumption is that mafias have to deal with a fundamental dilemma, that is, how to carry out their illegal activities in conditions of secrecy. And his main argument is that, in order to do so, these organizations establish norms to ensure the state of secrecy. The author observes that 'even if the context of criminal organizations is radically different from the context of legitimate organizations, mafias use organizational rules for the same reason legitimate organizations do: (1) to ensure organization, coordination and cooperation among their members and their organizational units. In addition to this function, mafias also need rules (2) to settle conflicts and to contain violence; and (3) to maintain secrecy and conceal information regarding their illegal activities from the outside' (Catino, 2015: 537). Because legitimate organizations do not need rules to settle dispute since they can rely on courts, and they require secrecy only in relation to a limited number of activities, what characterizes mafia rules is containment of violence and secrecy. To handle the diffusion of information is vital for keeping secrecy, and, as Simmel wrote, knowing how to say nothing is a required ability of secret societies. In mafias' culture, there is the term 'omertà,' which refers to specific behaviors associated with 
informational reticence, an attitude of silence, and the refusal of collaboration with the state. Omertà represents the code of honor, the implicit rule, which regulates mobs' behaviors in association with the explicit organizational rules governing secrecy. In fact, secrecy is the effect of organizational processes, and Catino examines three organizational practices, namely recruitment, initiation rites, and modes of introduction. Recruitment is highly selective, and it is one of the great strengths of the organization, which observes the subject's behavior in order to evaluate his/her criminal skills and depends on other members for assurance of criminal credentials and the trustworthiness of the potential candidates. Initiation rituals are the classical anthropological mechanisms for ratifying the rite of passage and the achievement of organizational identity and identification, since once in there is no way to retire. Finally, practices for introducing one member to another via a third person are needed, since one member cannot reveal his/her membership in mafia to another. These practices are meant to protect the organization from infiltrating agents and to delegate responsibility to the person performing the introduction, since, in the case of error, he/she will pay the price.

Shadow organizing in relation to the metonymy of secrecy reveals a way of intra-acting enacted by trust, personal bonds, and trading between what can be said and what cannot. Transparency and secrecy are two intra-acting elements in organizing. Moreover, the intra-acting of verbal and nonverbal communication points to forms of attachment to organizing activities situated at the affective level.

\section{Discussion}

We have used examples from the empirical research on organization to illustrate how the shadow organizing metaphor, as both a heuristic and 'world-making' device, is a cultural artifact which directs organizational scholars' attention to their implicit theories of organizing and the narratives they produce. Metaphorical thinking and talking facilitate the expression of feelings and perceptions that can be difficult to express verbally. In fact, we argue that the knowledge-generative power of 
metaphors has not being exhausted; rather, it should be developed further, as theorizing about organization explores new avenues. When we adventure into post-epistemologies and we want to explore how can we account for intra-actions instead of inter-actions, then the metaphor of shadow organizing can help us to explore the activities taking place in-between the light and the dark-in the ever changing penumbra-in the liminal space in-between canonical and non-canonical activities and in the in-between of transparency and secrecy. Shadow organizing is the effect of knowledgeable activities establishing connections between human and material elements, discourses and non-discursive elements' intended and unintended effects that 'just happen' in the process of agencement. The way in which connections take place and agency emerges is indeterminate, and therefore we can say that shadow organizing is a metaphor that enables us, as researchers, to connect to indeterminacy.

In Table 1 we summarize the metonymies we have proposed in order to illustrate shadow organizing as a specific organizing activity under the surface of rational, intentional, and explicit organizing. It is not opposed to planning or strategizing or other goal-directed ways of organizing; rather, it is a metaphor that works in their interstices, in the intra-acting, and in the becoming of intentional and unintentional ways of organizing.

The dimensions of shadow organizing that we have illustrated are as follows:

Performativity. The metonymy of the shadow as a protecting space, in which light and dark are entangled to form a penumbra, is based on a naturalistic image that on one side depicts the effect produced unintentionally by a big tree (shadow) and how this effect becomes the humus for other growing things/animals. A focal organization produces knowledge spillovers that nurture other forms of organizing, and therefore a knowledge spillover can be qualified as performative.

Liminality. The metonymy of the limen, like the ever-changing limit between the sand and the sea, is based on a naturalistic image where we look at the entanglement of solid/liquid elements in nature but can also be based on a social image such as a national border that divides and unites at the same time. In both cases what is represented - as in the penumbra - is a condition of being 
betwixt and between. Organizing processes in similar liminal activities are those pushing the borders between canonical and non-canonical practices, such as for professionals or frontline workers caught in-between the need to use discretion and to enforce organizational rules.

Secrecy. The metonymy of secrecy is based on a social transposition process in which the shadow stands for what should not be seen/said. Organizing processes that take place in order to protect organizational secrecy may be connected to illegal activities or morally disputable ones (but legal) or to the protection of knowledge in innovative activities. In all cases, the organizational activities are intentionally directed at keeping organizational secrecy and are based on more or less explicit organizational rules.

The three metonymies 'work' together in the sense that they help us to explore the metaphor of shadow organizing and use it as a tool for describing the intra-acting elements in the process of organizing according to their performativity, materiality, and discursivity.

\section{Conclusion}

Although metaphorical theorizing has a long tradition in organization studies, and it appears almost taken for granted, in reality, it is still a powerful tool for generating new insights (Oswick and Grant 2016). We argue that Morgan's legacy is particularly relevant nowadays at the moment in which organization studies are beginning to explore the potentiality of moving towards postepistemologies in which relationships among elements take the place of elements in relations. The passage from elements in interaction to intra-acting relations that form elements is a challenge for both theory and methodology. To face this challenge, metaphorical thinking may prove useful, since it enhances scholars' imagination and emotional participation. Moreover, a change in epistemology, from metaphor based on a static image (the machine, the organism, and so on) to metaphor based on process (like Morgan's flow and transformation and our shadow organizing), displaces the imagething for an image-process in Morgan and image-process-activity in our case. 
We have positioned our contribution within the literature on organizing. While organizing concerns giving form to equivocal flows, ordering, setting boundaries, around indefinite spaces, and developing structures (Weick, 1979), shadow organizing is about indeterminate effects taking place in the intra-actions of ordering processes, setting boundaries, and developing structures. It invites us to think of the human world as the transmission of mutable events, as 'the ceaseless work of alternation between the making of presence and the unmaking of absence' (Cooper, 2007: 1547). More generally we aim to contribute to those organization studies that take seriously Foucault (1977) heritage on power and regimes of visibility/invisibility. In fact, the issue of the always relational and recursive production of the visible and the invisible runs through the great classics of sociology (Brighenti, 2010) and interactionist studies on invisible work and work representation embedded in classifications and formalisms (Star and Strauss, 1999; Suchman et al., 1999), and infrastructure studies on scientific work (Fujimura, 1995; Bowker and Star, 1999). There has been a renewed attention set on the ecology of the visible and the invisible (Denis and Pontille, 2012) and the process of shadow organizing is inscribed in it.

We propose the metaphor of shadow organizing and the three metonymies on which we have based it - the shadow as a protective penumbra, the shadow as a grey zone between canonical and noncanonical practices, and the shadow as secrecy-in order to interpret and discuss the process of organizing as a form of intra-activity. Each metonymy offers a specific point of entry for the interpretation of the intra-acting elements, and when taken together, the three images make it possible to illustrate the dynamics of organizing in the interstices. The interstice, in its turn, may be regarded as a metaphor for intra-acting, since the epistemology of the term, from the Latin interstare, means to be in the in-between, to be in the middle. The sociology of interstices in everyday life (Gasparini, 1998) studies interstices of temporal experiences (waiting, pause, break), spatial experiences (travel, threshold, passage), or communicational experiences (silence, epistolary, phone call). What is distinctive of the interstice is being in-between and by extension the relationships inter-acting in a state of in-betweenness. 
In conclusion, the contribution of the metaphor of shadow organizing to theorizing about organizing is twofold. On one hand, shadow organizing focuses scholars' attention on the way that situated elements (people, technologies, knowledges, infrastructures, society) relate and become an agencement, that is, in being 'in connection with,' they acquire agency. On the other hand, shadow organizing enables a further qualification of the process of organizing, not only as a process of making connections but also as a process in which connections 'just happen.' Whilst organizing as the effect of intentional coordination, planning, and strategizing represents a well-established theorization, shadow organizing sheds light on what happens in the interstices of intentional and structured processes. We can say that shadow organizing looks at what happen 'in practice,' while organizational practices orient what should happen. In this sense, we can say that working practices are the site of shadow organizing, since a situated practice is the agencement of several elements intra-acting.

In proposing the metaphor of shadow organizing, we offer a view of a process of organizing as a situated and collective activity and not merely a temporality. Moreover, shadow organizing as an activity taking place in situated practices has the following dimensions: performativity, liminality, and secrecy. When we refer the metaphor to our own practices as researchers, we can say that we, as researchers, are not outside the phenomena we study and that our knowing arises from the emerging patterns of intra-action between material phenomena, the material arrangements for knowing about these phenomena, and knowledge practices. 


\section{References}

Alvesson, M. (1993), "The play of metaphors", in Hassard, J. and Parker, M. (Eds.), Postmodernism and Organizations, Sage, London, pp. 114-131.

Barad, K. (2003), "Posthumanist performativity: Toward an understanding of how matter comes to matter”, Signs, Vol. 28 No. 3, pp. 801-31.

Barad, K. (2007), Meeting the Universe Halfway: Quantum Physics and the Entanglement of Matter and Meaning, Duke University Press, Durham, NC.

Barley, S. (1983), "Semiotics and the study of occupational and organisational cultures," Administrative Science Quarterly, Vol. 28 No. 3, pp. 393-413.

Beech, N. (2011), "Liminality and the practices of identity reconstruction”, Human Relations, Vol. 64 No. 2, pp. 285-302.

Benozzo, A, Bell, H, \& Koro-Ljungber, M (2013). Moving between nuisance, splinters and secrets as data, Cultural Studies Critical Methodologies, 13(4), 309-315.

Bowker, G. and Star, S.L. (1999), Sorting Things Out: Classification and Its Consequences, MIT Press, Cambridge, MA.

Bowles, M. (1991), “The organization shadow”, Organization Studies, Vol. 12 No. 3, pp. 387-404.

Brighenti, A.M. (2010), Visibility in Social Theory and Social Research, Palgrave Macmillan, London.

Brown, R.H. (1976), "Social theory as metaphor: On the logic of discovery for the sciences of conduct", Theory and Society, Vol. 3 No. 2, pp. 169-197.

Callon, M. (2007), "What does it mean to say that economics is performative?” in MacKenzie, D. Muniesa, F., and Siu, L. (Eds.), Do Economists Make Markets? On the Performativity of Economics, Princeton University Press, Princeton, pp. 311-357. 
Cassell, C. and Bishop, V., (2014), "Metaphors and sensemaking: understanding the taint associated with dirty work", Qualitative Research in Organizations and Management: An International Journal, Vol. 9, No. 3, pp. $254-269$.

Cassell, C.M. and Lee, B. (2012), "Driving, steering, leading, and defending: journey and warfare metaphors of change agency in trade union learning initiatives", Journal of Applied Behavioral Science, Vol. 48 No. 2, pp. 248-271.

Catino, M. (2014), “How do mafias organize?”, European Journal of Sociology, Vol. 55 No. 2, pp. $177-220$.

Catino, M. (2015), "Mafia rules: The role of criminal codes in mafia organizations", Scandinavian Journal of Management, Vol. 31 No. 4, pp. 536-548.

Cooper, R., (1986), “Organization/Disorganization”, Information Science Information, Vol. 25 No. 2, pp. 299-335.

Cooper, R. (1992), "Formal organization as representation: remote control, displacement and abbreviation", in Hughes, M. and Reed, M. (Eds), Rethinking Organization: New Directions in Organization Theory and Analysis, Sage, London, pp. 254-272.

Cooper, R. (1998), "Assemblage notes", in Chia, R. (Ed.), Organized Worlds: Explorations in Technology and Organization with Robert Cooper, Routledge, London, pp. 108-129.

Cooper, R. (2005), “Relationality”, Organization Studies, Vol 26 No. 11, pp. 1689-1710.

Cooper, R. (2007), “Organs of process: Rethinking human organization”, Organization Studies, Vol. 28 No. 10, pp. 1547-1573.

Cooper, R. (2010), “The generalized social body: Distance and technology”, Organization, Vol. 17 No. 2, pp. 242-256.

Cooper, R. and Law, J. (1995), "Distal and Proximal Visions of Organization”, in Bacharach, S., Gagliardi, P. and Mundell, B. (Eds), Studies of Organizations in the European Tradition, Jai Press, Greenwich, pp. 237-274. 
Cornelissen, J.P., Holt, R., and Zundel, M. (2011), “The role of analogy and metaphor in the framing and legitimization of strategic change", Organization Studies, Vol. 32 No. 12, pp. 17011716.

Cornelissen, J. P., Kafouros, M., and Lock, A, (2005), "Metaphorical images of organization: How organizational researchers develop and select organizational metaphors”, Human Relations, Vol. 58 No. 12, pp. 1545-1578.

Costa, J. and Grey, C. (2014), "Bringing secrecy into the open: Towards a theorization of the social processes of organizational secrecy”, Organization Studies, Vol. 35 No, 10, pp. 1423-1447.

Cunliffe, A. L. (2003), "Reflexive inquiry in organizational research: questions and possibilities", Human Relations, Vol. 56 No. 8, pp. 983-1003.

Cyert, R. M. and March, J. G. (1963), A Behavioral Theory of the Firm, Englewood Cliffs, Prentice Hall, NJ.

Czarniawska, B. (2004), "Metaphors as enemies of organizing, or the advantages of a flat discourse”, International Journal of the Sociology of Language, Vol. 4 No. 166, pp. 45-65.

Czarniawska-Joerges, B. and Joerges, B. (1988), "How to control things with words: On organizational talk and organizational control”, Management Communication Quarterly, Vol. 2 No. 2, pp. $170-193$.

da Graça Batista, M., Clegg, S., Pina e Cunha, M., Giustiniano L., and Rego, A. (2016), "Improvising prescription: Evidence from the emergency room”, British Journal of Management, Vol. 27 No. 2, pp. $406-425$

Denis, J. and Pontille, D. (2012), "Workers of writing, Materials of information", Revue d'anthropologie des connaissances, Vol.6 No. 1, pp. a-s.

Foucault, M. (1977), Discipline and Punish: The Birth of the Prison, Penguin, London.

Freidson, E. (2001), Professionalism, the Third Logic: On the Practice of Knowledge. University of Chicago Press, Chicago. 
Fujimura, J., (1995), "Ecologies of action: recombining genes, molecularizing cancer, and transforming biology", in Star, S. L., (1995), Ecologies of Knowledge, Albany: State University of New York Press, pp.302-346.

Gasparini, G. (1998), Sociologia degli interstizi, Bruno Mondadori, Milano.

Gergen, K.J. (2012), “Co-constitution, causality, and confluence: Organizing in a world without entities", in Hernes, T. and Maitlis, S. (Eds.), Process, Sensemaking, and Organizing, Oxford University Press, Oxford, pp. 55-69.

Goffman, E. (1969), Strategic Interaction, University of Pennsylvania Press, Philadelphia.

Goodman, N. (1978), "Metaphor as moonlighting", in Sacks, S. (Ed.), On Metaphor, Chicago University Press, pp. 175-180.

Grant, D. and Oswick, C. (1996), Metaphor and Organisations, Sage Publications, London.

Guimarães-Costa, N. and Cunha, M. (2013), "The inevitability of liminality in organizing”, International Journal of Management Concepts and Philosophy, Vol. 7 No. 1, pp. 47-63.

Heracleous, L. (2003), “A Comment on the role of metaphor in knowledge generation”, Academy of Management Review, Vol. 28 No. 2, pp. 190-197.

Höpfl, H. and Maddrell, J. (1996), “Can you resist a dream? Evangelical metaphor and the appropriation of emotion”, in Grant, D. and Oswick, C. (Eds.), Metaphor and Organisations, Sage Publications, London.

Iedema, R. (2007), “On the multi-modality, materiality and contingency of organizational discourse", Organization Studies, Vol. 28 No. 6, pp. 931-946.

Knorr Cetina, K. (1997), "Sociology with objects. Social relations in postsocial knowledge societies", Theory, Culture \& Society, Vol. 14 No. 4, pp. 1-30.

Knorr Cetina, K. (2005), "Complex global microstructures: The new terrorist societies”, Theory, Culture \& Society, Vol. 2 No. 5, pp. 213-234.

Lakoff, G. and Johnson, M. (1980), Metaphors We Live By, University of Chicago Press, Chicago. 
Lather, P. and St. Pierre, E.A. (2013), "Post-qualitative research", International Journal of Qualitative Studies in Education, Vol. 26 No. 6, pp. 629-633.

Latour, B. (2005), Reassembling the Social, Oxford University Press, Oxford.

Law, J. (1987), “Technology and heterogeneous engineering: The case of the Portuguese expansion", in Bijker, W.E., Hughes, T.P., and Pinch, T.J. (Eds.), The Social Construction of Technical Systems: New Directions in the Sociology and History of Technology, Mit Press, Cambridge, Mass., pp. 111-134.

Law, J. (1994), Organizing Modernity, Blackwell, Oxford.

Lipsky, M. (2010), Street-level Bureaucracy: Dilemmas of the Individual in Public Services. 30th anniversary, expanded edition, Russell Sage Foundation, New York.

March, J. (1981), "Footnotes to organizational change", Administrative Science Quarterly, Vol. 26 No. 4, pp. 563-577.

Morgan, G. (1980), "Paradigms, metaphors and puzzle solving in organization theory", Administrative Science Quarterly, Vol. 25 No. 4, pp. 641-652.

Morgan, G. (1986), Images of Organizations, Sage Publications, London.

Morgan, G. (1996), "Is there anything more to be said about metaphor?”, in Grant, D. and Oswick, C. (Eds.), Metaphor and Organizations, SAGE, London, pp. 227-240.

Morgan, G. (2016), “Commentary: Beyond Morgan’s eight metaphors”, Human Relations, Vol. 69 No. 4, pp. 1029-1042.

Munari, F., Sobrero, M., and Malipiero, A. (2012), “Absorptive capacity and localized spillovers: focal firms as technological gatekeepers in industrial districts", Industrial and Corporate Change, Vol. 21 No. 2, pp. 429-462.

Oswick, C., and Grant, D. (2016), "Re-imagining images of organization: A conversation with Gareth Morgan”, Jornal of Management Inquiry, Vol. 25, No, 3, pp. 338-343.

Oswick, C., Keenoy, T., and Grant, D. (2002), “Metaphor and analogical reasoning in organization theory: Beyond orthodoxy", Academy of Management Review, Vol. 27 No. 2, pp. 294-303. 
Örtenblad, A., Putnam, L., and Treham, K. (2016), “Beyond Morgan's eight metaphors: Adding to and developing organization theory", Human Relations, Vol. 69 No. 4, pp. 875-889.

Putman, L., Phillips, N., and Chapman, P. (1997), "Metaphors of communication and organization", in Clegg, S.R., Handy, C., and Nord, W.R. (Eds.), Handbook of Organization Studies, Sage Publications, London.

Schoeneborn, D., Vasquez, C., and Cornelissen, J. (2016), "Imagining organization through metaphor and metonymy: Unpacking the process-entity paradox”, Human Relations, Vol. 69 No. 4, pp. 915-944.

Schon, D. (1979), “Generative metaphor. A perspective on problem setting in social policy”, in Ortony, A. (Ed.), Metaphor and Thought, Cambridge University Press, Cambridge, UK, pp. 254 283.

Simmel, G. (1906), "The sociology of secrecy and of secret societies", American Journal of Sociology, Vol. 11 No. 4, pp. 441-498.

Star, S. L., and Strauss A. (1999), "Layers of silence, arenas of voice: the ecology of visible and invisible work", Computer-Supported Cooperative Work: The Journal of Collaborative Computing, Vol. 8, pp. 9-30.

Suchman, L., Blomberg, J. Orr, J.E. and Trigg, R. (1999), "Reconstructing technologies as social practice", American Behavioural Scientist, Vol. 43, pp. 392-408.

Tsouskas, H. (1991), “The missing link: a transformational view of metaphors in organizational sciences", Academy of Management Review, Vol. 16 No. 3, pp. 566-585.

Turner, V. (1969), The Ritual Process. Structure and Anti-Structure, Aldine, Chicago, IL. Venn, C. (2006), A note on assemblage, Theory, Culture \& Society, Vol. 23, No. 2-3, pp. 107-108. Weber, M. (1922), Wirtschaft und Gesellschaft, Mohr, Tübingen.

Weick, K. (1979), The Social Psychology of Organizing (2nd ed.), Addison-Wesley, New York, NY. 
Weick, K. E. and K. M. Sutcliffe (2007), Managing the Unexpected: Resilient Performance in an Age of Uncertainty, second edition, Jossey-Bass, San Francisco, CA.

\footnotetext{
'The metaphor of the organization shadow has been proposed by Bowles (1991), who grounds it in Jungian psychology, where the shadow of an organization refers to everything of which an organization is not fully conscious. Bowles employs this metaphor in order to discuss the things that an organization wants to deny about itself and the things that it tends to project onto others. We acknowledge Bowles' contribution; nevertheless, we are not going to develop it here since our main interest is devoted to organizing and not organization.

ii We are grateful to the anonymous reviewer who reminded us of the great influence that Robert Cooper had on the development of a relational ontology and on the subsequent debate on post-epistemologies.
} 
Table 1: Three ways of configuring shadow organizing

\begin{tabular}{|c|c|c|}
\hline $\begin{array}{l}\text { Metonymies of } \\
\text { shadow }\end{array}$ & $\begin{array}{l}\text { Shadow organizing processes and literature } \\
\text { example }\end{array}$ & $\begin{array}{l}\text { Dimensions of shadow } \\
\text { organizing }\end{array}$ \\
\hline $\begin{array}{l}\text { The protecting space } \\
\text { that penumbra } \\
\text { provides in a forest. }\end{array}$ & $\begin{array}{l}\text { Organizing processes taking place 'in an } \\
\text { ecological niche'. Organizational devices - } \\
\text { like knowledge spillovers - produce effects } \\
\text { on their object. They are performative. } \\
\text { Es: Munari et al. (2012) }\end{array}$ & Performativity \\
\hline $\begin{array}{l}\text { The liminal, grey zone } \\
\text { between canonical and } \\
\text { non-canonical } \\
\text { practices }\end{array}$ & $\begin{array}{l}\text { Liminal activities in the process or } \\
\text { becoming structure or remaining anti- } \\
\text { structure. } \\
\text { Es: da Graça Batista et al. (2016) }\end{array}$ & Liminality \\
\hline $\begin{array}{l}\text { Secrecy and secret } \\
\text { societies }\end{array}$ & $\begin{array}{l}\text { Organizing processes that should stay } \\
\text { hidden or unspoken. More or less illegal } \\
\text { activities or morally disputable ones. } \\
\text { Es: Catino (2015) }\end{array}$ & $\begin{array}{l}\text { Secrecy: what is said } \\
\text { (and what can be said) } \\
\text { and what should be } \\
\text { kept unsaid. }\end{array}$ \\
\hline
\end{tabular}

